\title{
FRANCISCO LINARES MARTÍNEZ (2018): Sociología y teoría so- cial analíticas Madrid, Alianza editorial.
}

En su seminal obra sobre La lógica de la acción colectiva, Mancur Olson (1971) define un "grupo privilegiado" como aquel en el que alguno de sus miembros tiene incentivos suficientes para procurar que un bien colectivo sea suministrado incluso si él mismo tiene que cargar con el coste total de la provisión del bien. En este sentido preciso, la teoría social española de corte analítico tiene el privilegio de contar con su primera síntesis teórica original -existían algunos buenos compendios y traducciones anteriores- en la obra de Francisco Linares. En un sentido más amplio, la sociología española tiene el privilegio de recibir un excelente texto de teoría sociológica.

Sociología y teoría social analíticas es un libro de teoría social que presenta dos novedades muy importantes con respecto a los manuales al uso. La primera es que no se trata de una compilación de los pensamientos de sociólogos clásicos o modernos, sino de un libro de iniciación a cómo hacer teoría social, y este es el primero de los grandes aciertos del mismo. Así, se acerca bastante al modo en el que se enseña la teoría sociológica en cursos de posgrado de enorme prestigio, como el impartido bajo el título Sociological Analysis en el departamento de sociología de la Universidad de Oxford. A lo largo del libro, el lector se va encontrando una serie de temas de gran calado sociológico que van desde cuestiones metateóricas como la explicación en ciencias sociales, hasta temas clásicos de la teoría social como el individualismo, la acción colectiva o el vínculo micro-macro, pasando por aspectos eminentemente prácticos y novedosos como la construcción teórica a partir de modelos de simulación multiagente.

La segunda novedad que presenta el libro es que tiene una - $\mathrm{O}$ varias- tesis que lo alejan de aquella manida formulación de la sociología como "ciencia multiparadigmática" (sobre esta ver el articulo de Noguera, 2010). Más bien se encuadra en una tradición del pensamiento sociológico que tan bien resumió Raymond Boudon (2002) en su famosa intervención ante la European Academy of Sociology y cuyo título era la "Sociología que realmente importa". Boudon es, junto a Robert K. Merton, Jon Elster y James S. Coleman, una de las referencias que han cimentado la tradición analítica que ahora nos acerca Francisco Linares. Pero hay más tesis en el libro, algunas de las cuales son sorprendentemente específicas y uno podría pensar que incluso arriesgadas en una disciplina -la sociología- tan acostumbrada a aquello del todo vale. A modo de ejemplo, voy a detenerme en tres de las principales apuestas del libro, dos teóricas y una metodológica. La primera se encuentra en el mismo subtítulo de la obra que define a la sociología 
como la ciencia de las consecuencias inintencionadas de la acción. Aquí sigue la distinción hecha por otro gigante del pensamiento social, Vilfredo Pareto, que distinguía entre acciones (humanas) lógicas (o racionales) y no lógicas (o no racionales), afirmando que la ciencia económica se había ocupado exclusivamente de las primeras y proponiendo que la sociología centrara su análisis en las segundas. La segunda apuesta teórica es la elección del mecanismo de "imitación racional" como el principio subyacente al tipo de conducta social -aquella que genera consecuencias inintencionadas- que interesa a la sociología. Por último, el libro entiende la sociología de un modo generativo y apuesta por la simulación multiagente como el método privilegiado para la construcción de teoría sociales.

Un libro tan ambicioso como el que nos ocupa tiene necesariamente varias lecturas y en esta reseña quisiera resaltar tres de estas. Una primera lectura, y quizá la que interese a un público más amplio, tiene que ver con una presentación crítica de las principales aportaciones de la teoría sociológica de la segunda mitad del siglo XX. Francisco Linares argumenta convincentemente cómo las aportaciones sociológicas con un carácter más analítico han sobrevivido mejor al paso del tiempo que las grandes aproximaciones macrosociológicas (funcionalismo, estructuralismo) del siglo pasado. Al contrario que estas, la tradición analítica apostaría por el tipo de teorías de rango medio que nos proponía Merton y por la idea del individualismo estructural, es decir, por una construcción teórica que pone el foco en el individuo, pero no en el individuo aislado de la teoría económica, sino en un individuo situado o incrustado socialmente. Sin duda, se trata de un libro que ocupará un lugar privilegiado en la enseñanza de la teoría sociológica en castellano.

Pero el libro tiene al menos dos lecturas más. Por una parte, el libro supone un intento de dotar de microfundamentos a la teorización sociológica. Unos microfundamentos propios, distintos a los del atomismo de la teoría económica y donde la interacción social ocupa el centro de la escena. Es aquí donde Francisco Linares se compromete de un modo más claro con una determinada teoría social analítica: un compromiso teórico con el principio de "imitación racional" y un compromiso metodológico con el uso privilegiado de los modelos de simulación multiagente.

Finalmente, un hilo conductor alternativo del libro es una reconstrucción de la corriente sociológica denominada analítica, en general, y de su implantación en España, en particular. Aquí de nuevo el autor toma partido de forma clara, apostando por una definición de la sociología analítica que encuentra su principal exponente en los trabajos de Peter Hedström, especialmente su Dissecting the Social (2005). Esta elección también está cargada de sentido, ya que otros textos ampliamente citados en la tradición analítica -véase el artículo de Herbert Gintis (2006) en el monográfico sobre teoría sociológica analítica de la revista Papers - abogarían por la confluencia de este tipo de sociología con desarrollos paralelos en otras disciplinas colindantes, como la economía, psicología o ciencia política conductuales. Una alternativa a una demarcación clara de las fronteras de la disciplina sociológicoanalítica sería la de construir una ciencia social unificada donde tuvieran cabida los desarrollos recientes de las distintas disciplinas sociales.

Como bien queda reflejado en este excelente libro de Francisco Linares, en las ciencias sociales contemporáneas empieza a existir un consenso generalizado acerca del pluralismo motivacional en la acción humana humano. Pues bien, el lector encontrará igualmente una pluralidad de razones para leer y disfrutar de Sociología y teoría social analíticas: para 
preparar las clases de introducción a la sociología o teoría social, para disfrutar de un ameno repaso por la historia de la teoría sociológica contemporánea o para entender mejor los fundamentos de una disciplina que pretende ser central en el panorama científico del siglo XXI.

\section{Referencias bibliográficas:}

BOUDON, R. (2002), "Sociology that Really Matters", European Sociological Review, Vol. 18, pp. 371-378.

GINTIS, H. (2006), "Towards a Unity of the Human Behavioral Sciences ", Papers, Vol. 80, pp. 97-122.
HEDSTRÖM, P. (2005), Dissecting the Social: On the Principles of Analytical Sociology, Cambridge, Cambridge University Press.

NOGUERA, J.A. (2010), "El mito de la sociología como «ciencia multiparadigmática»", Isegoría, $\mathrm{N}^{\circ} 42$, pp. 31-53.

OLSON, M. (1971), The Logic of Collective Action. Publics Goods and the Theory of the Groups, Cambridge (MA), Harvard University Press.

Luis Miguel Miller Moya Universidad del País Vasco 
